\title{
Protocol for characterizing the molar mass distribution and oxidized functionality profiles of aged transformer papers by gel permeation chromatography (GPC)
}

\author{
Paul Jusner (D) Florian Bausch (D) \\ Sonja Schiehser (D) Elisabeth Schwaiger * \\ Antje Potthast 1 - Thomas Rosenau $(\mathbb{D}$
}

Received: 13 December 2021 / Accepted: 28 January 2022 / Published online: 15 February 2022

(C) The Author(s) 2022

\begin{abstract}
Oil-immersed paper insulation and paper pressboards for structural support are widely used in electrical power transformers. Cellulose thus fulfills an essential task for the smooth power supply of our societies. However, the prevailing temperatures in such equipment, combined with a targeted service life of several decades, pose a serious challenge to the long-term integrity of cellulosic paper insulation. Therefore, numerous studies have been conducted to obtain kinetic data on the degradation processes that contribute to the thermally induced decomposition of cellulose. These studies usually rely on the
\end{abstract}

Supplementary Information The online version contains supplementary material available at https://doi. org/10.1007/s10570-022-04464-2.

P. Jusner · F. Bausch $\cdot$ S. Schiehser $\cdot$ A. Potthast $(\square)$.

T. Rosenau $(\bowtie)$

Department of Chemistry, Institute of Chemistry

of Renewable Resources, University of Natural Resources and Life Sciences Vienna (BOKU), Konrad-Lorenz-Straße

24, 3430 Tulln, Austria

e-mail: antje.potthast@boku.ac.at

T. Rosenau

e-mail: thomas.rosenau@boku.ac.at

E. Schwaiger

Mondi Frantschach GmbH, Frantschach 5,

9413 St., Gertraud, Austria

T. Rosenau

Johan Gadolin Process Chemistry Centre, Åbo Akademi

University, Porthansgatan 3, 20500 Åbo/Turku, Finland assessment of the average degree of polymerization by viscosity measurements. In this work, we applied and optimized more advanced methods for the characterization of cellulosic materials based on gel permeation chromatography for the special case of thermally stressed unbleached Kraft paper samples. This allowed studying the molar mass distributions of paper polymers upon exposure to heat, as well as the investigation of changes in their conformation in solution and the observation of thermally induced cross-linking. In combination with group-selective fluorescence labeling, it was possible to track over time the changes in molar mass-dependent profiles of carbonyl and carboxyl groups of authentic Kraft insulator paper samples under thermal stress. In addition, changes of the hemicellulose composition were quantified. We hope that this analytical approach to the in-depth characterization of thermally stressed insulator paper will prove useful for future studies of this important cellulose product, and that our findings will contribute to a better understanding of the thermal decomposition of paper in general. 


\section{Graphical abstract}

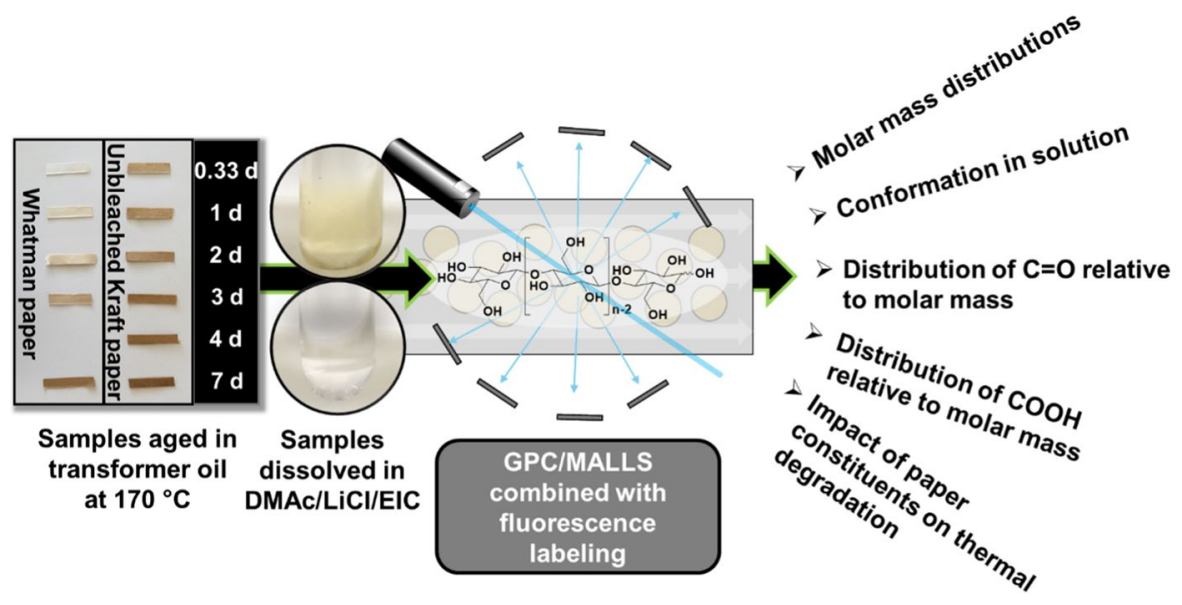

Keywords Cellulose $\cdot$ Kraft paper $\cdot$ Thermal ageing $\cdot$ Accelerated ageing $\cdot$ Molar mass distribution $\cdot$ Gel permeation chromatography $\cdot$ Size exclusion chromatography $\cdot$ Crosslinking

\section{Introduction}

Cellulosic materials have been employed as electrical insulators in cables and all kind of electrical devices since the earliest days of electrical engineering. Oilimmersed paper insulators are still widely used in electrical power transformers and high voltage power cables (Prevost and Oommen 2006), essentially because cellulosic materials feature excellent electrical insulation properties in dry state combined with high availability and a relatively low price. Due to good mechanical properties at elevated temperatures compared to synthetic and more expensive polymer alternatives, paper pressboards additionally serve as mechanical support in oil-filled power transformers. For such purposes, unbleached Kraft pulp derived from softwood species is primarily used as the raw material (Krause 2012). Apart from exclusion of water and oxygen from the system, the temperatures in such transformers must be kept as low as possible to guarantee the paper insulators' integrity throughout the targeted lifespans of several decades. Typically, the average operating temperatures stay in the range of 65 to $95^{\circ} \mathrm{C}$ (Emsley and Stevens 1994b). Nonetheless, long-term exposure of certain parts of the paper insulation to $100{ }^{\circ} \mathrm{C}$ and more is not uncommon
(Krause et al. 2014). If the cooling system fails or an electrical fault or short-circuit occurs, these temperatures are easily surpassed. In case of partial discharges, the local temperature peak to which the insulators are subjected may momentarily even surpass $1000{ }^{\circ} \mathrm{C}$ ( $\mathrm{Li}$ et al. 2020). Such conditions inevitably lead to a slow but steady degradation of cellulosic papers. Nonetheless, with good maintenance and if no severe faults occur, cellulosic insulators usually serve their purpose for up to 40 years without the need for replacement (Jalbert et al. 2014).

If the degree of polymerization of cellulose falls below a certain level, mechanical properties of paper insulators are lost and a fatal short circuit is likely to happen. The commonly accepted end of a paper insulator's life is reached when the average degree of polymerization (DP) drops below a value of 200 glucose monomers (Lundgaard et al. 2004). In experiments conducted with authentic softwood Kraft paper samples, commonly used for insulator papers, the DP has usually been determined by means of viscosity measurements after dissolving the samples in organometallic solvents (Soares et al. 2001; Lundgaard et al. 2004; Jalbert et al. 2014; Arroyo-Fernandez et al. 2017), despite the fact that these solvents afford only a sum parameter and afford incorrect values 
especially for oxidized pulps (Ahn et al. 2019a; Zaccaron et al. 2020). In those cases, the "real" average DP is certainly underestimated because the alkaline organometallic solvents trigger chain cleavage of the cellulose polymers by $\beta$-alkoxy elimination processes. Alternatively, attempts have been made to study thermally stressed Kraft paper samples after dissolution in a saturated N,N-dimethylacetamide/ lithium chloride solution $(\mathrm{DMAc} / \mathrm{LiCl})$ by means of gel permeation chromatography (GPC) (Chrapava et al 2003; Potthast et al. 2015), but the authors mentioned that complete sample dissolution was not achieved (Kes and Christensen 2013). Rising the temperature during sample dissolution may be effective, but only because of severe cellulose degradation due to thermal formation of keteneiminium ions which are reagents that particularly target glycosidic bonds (Potthast et al. 2002a, b). So far, more sophisticated studies of thermally stressed, oil-immersed paper including the analysis of molar mass distributions (MMDs) obtained via GPC employing a DMAc/LiCl solvent system were limited to model experiments with paper from cotton linters (Emsley et al. 2000) or to cellulose tricarbanilate derivatives of Kraft paper samples employing tetrahydrofuran as solvent (Hill et al. 1995). However, the latter approach is incompatible with fluorescence labeling techniques of oxidized functionalities. Most studies were conducted to derive decomposition kinetics of paper insulators and thus, to predict the life expectancy under certain conditions in real power transformers (Emsley and Stevens 1994a), with a reliable prediction of the current DP based on paper degradation products in the transformer oil samples as the ideal outcome.

The aim of this work was to extend the analytical toolbox for the hard-to-analyze insulation paper samples by developing a reliable protocol for dissolving thermally stressed unbleached Kraft paper in the non-degrading cellulose solvent $\mathrm{DMAc} / \mathrm{LiCl}$ for GPC analysis (Henniges et al. 2011, 2014; Potthast et al. 2015). This was key to studying molecular weight distributions and carbonyl/carboxyl group profiles of authentic insulation paper samples and to significantly increasing the information potential of such ageing studies compared to previous approaches.

\section{Materials and methods}

Materials Handsheets were prepared from unbleached Kraft pulp (UKP) by using a Rapid Köthen sheet former without extensive beating prior to sheet formation $\left(15^{\circ} \mathrm{SR}\right)$. The wet sheets were pressed for $10 \mathrm{~min}$ at $92{ }^{\circ} \mathrm{C}$ and -1 bar. The pulp sample was kindly supplied by Mondi Frantschach GmbH, Austria. Whatman paper No. 1 (pure cotton cellulose; WP) was used for comparison as received. Both UKP and WP had a grammage of $87 \mathrm{~g} / \mathrm{m}^{2}$. UKP had an average lignin content of $4.9 \mathrm{wt} \%$ (determined with the acetyl bromide method according to Dence (1992), $n=3$ ) and an average hemicellulose content of $93.6 \mu \mathrm{g} / \mathrm{mg}$ (determined with acidic methanolysis and subsequent monosaccharide quantification according to Sundberg et al. 1996 and Becker et al. 2021, $\mathrm{n}=2$ ). All solvents used for this work were purchased from SigmaAldrich (Merck KGaA, Germany) and of the highest purity available. $\mathrm{H}_{2} \mathrm{O}$ was deionized prior to utilization for sample preparation.

Ageing procedure The aged sample sets characterized in this study have also been used in previous work (Jusner et al. 2021a). UKP and WP samples were cut into stripes (width $=5 \mathrm{~mm}$, maximum length $=2.5 \mathrm{~cm}$, with ceramic scissors) and transferred into $20 \mathrm{~mL}$ borosilicate glass ampoules ( $0.125 \mathrm{~g}$ per sample). Before closing the ampoules, the samples were dried for $72 \mathrm{~h}$ at $40{ }^{\circ} \mathrm{C}$ in a vacuum oven and subsequently stored at room temperature (RT) in a desiccator for $48 \mathrm{~h}$ over $\mathrm{P}_{4} \mathrm{O}_{10}$ with vacuum applied. Then, the desiccator was flushed with argon for $5 \mathrm{~min}$ and $10 \mathrm{~g}$ of dry Nynas Nytro 4000X transformer oil (Nynas AB, Sweden) was added to each sample. The desiccator was evacuated until bubbles formation in the oil subsided and was flushed again with Ar. The ampoules were sealed and the samples were aged at $170{ }^{\circ} \mathrm{C}$ for up to 14 days (sampling of UKP after $0,0.33,1,2,3,4,7,10$, and 14 days; sampling of WP after $0,0.33,1,2,3,7$, and 14 days). Subsequently, the transformer oil was removed by accelerated solvent extraction (ASE) with n-heptane at around 115 bar and $40{ }^{\circ} \mathrm{C}$ for $2 \mathrm{~h}$.

$\mathrm{NaClO}_{2}$ treatment The heptane extracted UKP samples were subjected to a $\mathrm{NaClO}_{2}$ treatment for lignin removal. Each sample $(0.125 \mathrm{~g})$ was swollen in $\mathrm{H}_{2} \mathrm{O}$ overnight, rinsed with acetone over a Büchner funnel and treated with 3 portions of $0.042 \mathrm{~g}$ of $\mathrm{NaClO}_{2}$ dissolved in acetate buffer $(\mathrm{pH} 5 ; 1$ st portion 
dissolved in $12.5 \mathrm{~mL}, 2 \mathrm{nd}$ and 3rd portion dissolved in $6.25 \mathrm{~mL}$ ). The $1 \mathrm{st}$ portion was added to the sample and the suspension was left stirring in a water bath at $40{ }^{\circ} \mathrm{C}$. The 2 nd addition of $\mathrm{NaClO}_{2}$ solution was after $2 \mathrm{~h}$ and the 3rd addition after $4 \mathrm{~h}$. The sample was removed from the water bath after $6 \mathrm{~h}$ by filtration and rinsed with $\mathrm{H}_{2} \mathrm{O}$ until the filtrate reached a neutral $\mathrm{pH}$ value.

Fluorescence labelling $20 \mathrm{mg}$ of air-dried (moisture content $<10 \mathrm{wt} \%$ ) sample material $\left(\mathrm{NaClO}_{2}\right.$-treated UKP and non-treated WP) were disintegrated for $20 \mathrm{~s}$ in $0.25 \mathrm{~L}$ of $\mathrm{H}_{2} \mathrm{O}$ (for CCOA labelling) or in $0.25 \mathrm{~L}$ of aqueous $0.1 \mathrm{M} \mathrm{HCl}$ solution (for FDAM-labelling) using a kitchen blender. The samples were filtered and subjected to fluorescence-labelling with carbazole-9-carbonyl-oxy-amine ("CCOA") and 9H-fluoren-2-yl-diazomethane ("FDAM") according to the standard protocols (Röhrling et al. 2002a and 2002b, Potthast et al. 2003, Bohrn et al. 2006). All samples were prepared in duplicate.

The CCOA method (carbonyl group labeling) in brief: after disintegration, the samples were transferred into a $4 \mathrm{~mL}$ vial and $4 \mathrm{~mL}$ zinc acetate buffer (pH 4) containing $5 \mathrm{mg}$ of CCOA were added to each sample. The samples immersed in the labelling solution were vortexed and left shaking in a water bath at $40{ }^{\circ} \mathrm{C}$ for 7 days.

The FDAM method (carboxyl group labeling) in brief: after disintegration and protonation, the samples were solvent-exchanged to $\mathrm{N}, \mathrm{N}$-dimethylacetamide (DMAc) via ethanol, transferred into a $4 \mathrm{~mL}$ vial and left shaking in $3 \mathrm{~mL}$ of DMAc overnight. Subsequently, $1 \mathrm{~mL}$ of DMAc containing ca. 0.125 mmol FDAM was added. The samples in the labelling solution were vortexed and left shaking in a water bath at $40{ }^{\circ} \mathrm{C}$ for 7 days.

Sample dissolution Samples were dissolved by means of an adjusted procedure introduced by Berthold et al. (2004). CCOA-labelled samples and non-labelled samples $(20 \mathrm{mg}$, air-dry, disintegrated in $0.25 \mathrm{~L} \mathrm{H}_{2} \mathrm{O}$; MMDs of non-labelled samples in Figure S3 and Figure S4) were solvent exchanged to DMAc via ethanol, transferred into a $4 \mathrm{~mL}$ vial, and left shaking in $3 \mathrm{~mL}$ of DMAc overnight. As FDAMlabelling takes place in DMAc, only a washing step with DMAc, but no solvent exchange, was necessary prior to sample dissolution. The DMAc-wet samples were transferred into $12 \mathrm{~mL}$ vials and dissolved by adding $2 \mathrm{~mL}$ of freshly prepared $\mathrm{DMAc} / \mathrm{LiCl}(9 \%$, w/v) to each sample followed by shaking for a total of 7 days at RT. $24 \mathrm{~h}$ after addition of $\mathrm{DMAc} / \mathrm{LiCl}$, $0.15 \mathrm{~mL}$ of ethyl isocyanate (EIC) was added to each sample vial. Immediately after the EIC addition, the vial was closed and vortexed for 30 s. After 7 days, $6 \mathrm{~mL}$ of DMAc was added to each vial followed by $0.3 \mathrm{~mL}$ of methanol. The vial was vortexed for $30 \mathrm{~s}$ and left to rest for $1 \mathrm{~h}$. For GPC analysis, a $1 \mathrm{~mL}$ aliquot of each sample was filtered through a $0.45 \mu \mathrm{m}$ syringe filter into a $1.5 \mathrm{~mL}$ vial.

GPC analysis The components of the GPC system were: a multi-angle laser light scattering (MALLS) detector (Wyatt Dawn DSP, Wyatt Inc., Santa Barbara, CA, USA) with an argon ion laser $(\lambda=488 \mathrm{~nm})$, a refractive index (RI) detector (Shodex RI-71, Showa Denko K.K., Tokyo, Japan), fluorescence detectors (for CCOA-labelled samples: TSP FL3000, Spectra System, Thermo Fisher Scientific, Waltham, MA, USA, $\lambda_{\mathrm{ex}}=290, \lambda_{\mathrm{em}}=340 \mathrm{~nm}$; for FDAM-labelled samples: RF-553 Fluorescence HPLC detector, Shimadzu Corporation K.K., Kyoto, Japan, $\lambda_{\mathrm{ex}}=280 \mathrm{~nm}$, $\lambda_{\text {em }}=312 \mathrm{~nm}$ ), a Bio-Inert 1260 Infinity II pump (Agilent, Waldbronn, Germany), a HP Series 1100 autosampler (Agilent, Waldbronn, Germany), and 4 serial GPC columns (PLgel-mixed ALS, $20 \mu \mathrm{m}$, $7.5 \times 300 \mathrm{~mm}$, Agilent, Waldbronn, Germany). $\mathrm{DMAc} / \mathrm{LiCl}(0.9 \%, \mathrm{w} / \mathrm{v})$, filtered through a $0.02 \mu \mathrm{m}$ filter, was used as eluent, the flow rate was $1 \mathrm{~mL} / \mathrm{min}$, the injection volume $100 \mu \mathrm{L}$, and the measurement time per sample $45 \mathrm{~min}$. The square-shaped aperture was chosen for the fluorescence detector (TSP FL3000) instead of the slit-shaped aperture. The raw data was processed with Astra 4.7 (Wyatt Technologies), GRAMS/AI 7.0 software (Thermo Fisher Scientific), and Chromeleon software (Thermo Fisher Scientific), affording the molar mass parameters $M_{n}$, $\mathrm{M}_{\mathrm{w}}, \mathrm{M}_{\mathrm{z}}$, and $\mathrm{D}_{\mathrm{M}}$. The molar mass parameters were obtained by linear fitting of the raw data in GRAMS/ AI 7.0 (see Figure S2 for examples).

Acidic methanolysis and monosaccharide quantification Low-molecular weight carbohydrates were quantified according to Sundberg et al. (1996) and Becker et al. (2021). Freeze-dried sample material (8 to $9 \mathrm{mg}$ ) was weighed into a $10 \mathrm{~mL}$ test tube. Each analysis was performed in duplicate. $2 \mathrm{M} \mathrm{HCl}$ solution in anhydrous methanol (2 $\mathrm{mL})$ was added, vortexed for $2 \mathrm{~min}$ at RT, and heated to $100{ }^{\circ} \mathrm{C}$ for $5 \mathrm{~h}$. Samples were vortexed every $15 \mathrm{~min}$. After the samples had cooled to RT, $0.4 \mathrm{~mL}$ of anhydrous pyridine 
was added, followed by another short vortex treatment. $0.2 \mathrm{~mL}$ of a D-sorbitol solution in anhydrous methanol ( $c=5 \mathrm{mg} / \mathrm{mL}$, purity $\geq 98 \%$, Sigma Aldrich, Germany) were added as the internal standard. The solvents were evaporated overnight under a constant $\mathrm{N}_{2}$ stream. Afterwards, $0.2 \mathrm{~mL}$ of anhydrous pyridine was added, the samples were vortexed, and left for equilibration for $1 \mathrm{~h}$. $0.2 \mathrm{~mL}$ of anhydrous pyridine containing $1.5 \mathrm{mg}$ of 4-(dimethylamino)pyridine (purity $\geq 99 \%$, Sigma Aldrich, Germany) per $\mathrm{mL}$ of pyridine was added as well as $0.4 \mathrm{~mL}$ of N,Obis(trimethylsilyl)-trifluoroacetamide (purity $\geq 99 \%$, Sigma Aldrich, Germany) containing 10\% trimethylchlorosilane (purity $\geq 99 \%$, Sigma Aldrich, Germany). The samples were vortexed at RT, heated to $70{ }^{\circ} \mathrm{C}$ for $2 \mathrm{~h}$ and stored at $-20{ }^{\circ} \mathrm{C}$ for $15 \mathrm{~min}$. The sample mixtures were diluted with $0.8 \mathrm{~mL}$ of ethyl acetate, vortexed at RT, and centrifuged. Three xylan samples were treated analogously to determine the recovery rate $(114.99 \%)$, which was considered for calculation of the results.

The samples were transferred into $1.5 \mathrm{~mL} \mathrm{GC}$ vials and $1 \mu \mathrm{L}$ was injected (injector temperature: $260^{\circ} \mathrm{C}$, split ratio of 10:1) into the GC-FID system (Agilent 7890B, Agilent Technologies Inc., Mississauga, ON, Canada). For the analysis, a HP1 methyl siloxane column (Agilent 19091Z-413: $30 \mathrm{~m} * 320 \mu \mathrm{m} * 0.25 \mu \mathrm{m}$, Agilent Technologies Inc., Santa Clara, CA, USA) was used, with $\mathrm{H}_{2}$ as the carrier gas at a flow rate of $2 \mathrm{~mL} / \mathrm{min}$. Initially, the oven temperature was kept at $140{ }^{\circ} \mathrm{C}$ for $1 \mathrm{~min}$, increased to $210{ }^{\circ} \mathrm{C}$ at a rate of $4 \mathrm{~K} /$ min, and then further increased to $260{ }^{\circ} \mathrm{C}$ at a rate of $30 \mathrm{~K} / \mathrm{min}$ with a hold time of $5 \mathrm{~min}$. The detector temperature was kept at $280{ }^{\circ} \mathrm{C}$. The FID temperature was maintained at $320{ }^{\circ} \mathrm{C}$ with a $\mathrm{H}_{2}$ flow of $30 \mathrm{~mL} /$ min. The retention time of the individual methyl glycosides was calibrated by means of commercially available standards of highest purity. The FID signal was evaluated utilizing Agilent ChemStation software (Agilent Technologies Inc., Santa Clara, CA, USA).

\section{Results and discussion}

In this work, oil-immersed Kraft paper (UKP) and Whatman paper (WP) samples were subjected to accelerated aging at $170{ }^{\circ} \mathrm{C}$ for up to 14 days. Under standard operating conditions, $170{ }^{\circ} \mathrm{C}$ is well above temperatures expected in power transformers, yet $170{ }^{\circ} \mathrm{C}$ is not far from hot-spot temperatures and temperatures that occur if overloads are applied or problems with the cooling system occur. Thus, this temperature seemed to be the perfect compromise between overly drastic conditions causing cellulose degradation within less than days and too mild conditions that would require extensive observation times. Moreover, samples prepared in this way seemed to be rewarding challenges to train the analytical methods and explore its limits. While the Kraft pulp was the same that is used in technical power transformers, the Whatman counterpart served as a "blank" consisting of pure cellulose so that effects of hemicelluloses could be sorted out.

Sample dissolution

The protocol for the dissolution of the thermally stressed UKP prior to GPC analysis is schematically
Fig. 1 Overview of sample preparation protocol for GPC analysis. Fluorescence labelling $(\mathbf{4 A})$ is an optional step, as is $\mathrm{DP}_{\mathrm{v}}$ determination by viscosity measurements (4B)

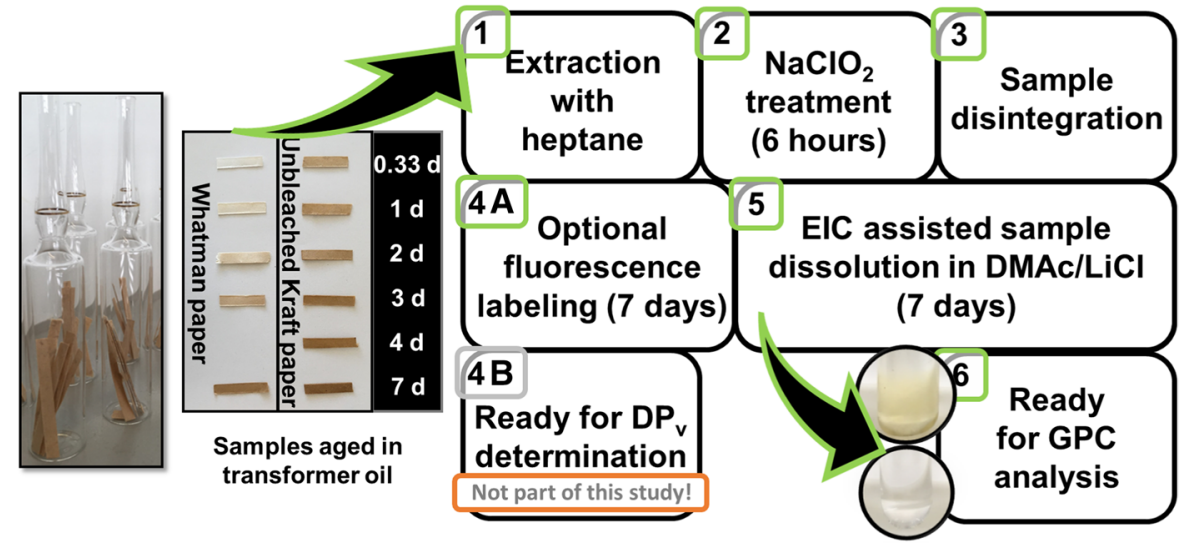


depicted in Fig. 1. To study whether the MMD, the conformation of carbohydrates in solution, and the distribution of oxidized functionalities along their backbone change independently of the sample composition or not, the pure-cellulose Whatman paper was analyzed in parallel. The first step was to remove transformer oil residues from the samples with n-heptane by accelerated solvent extraction (ASE) (step 1 in Fig. 1). Afterwards the UKP samples were treated with a $\mathrm{NaClO}_{2}$ /acetate buffer solution ( $\mathrm{pH} 5)$ to remove the lignin. Otherwise, dissolution of softwood Kraft pulp samples in the GPC eluant would be impossible (Sjöholm et al. 1997; Berthold et al. 2004; Henniges et al. 2011, 2014). This treatment neither reduces the molar mass of unaged UKP reference samples, nor does it affect the polymer conformation in solution (cf. Figure S3). However, it slightly decreases the xylose fraction and increases the glucose fraction susceptible to acidic methanolysis (cf. Table S1 and Table S2). Furthermore, it slightly reduces the crystallinity of UKP samples (cf. Table S1 and Table S2). This pre-treatment (step 2 in Fig. 1) effected complete dissolution of thermally stressed UKP samples by means of the DMAc/LiCl/EIC system. Although the detailed action mechanism of the EIC auxiliary is still not fully clarified, its beneficial effect on the dissolution of cellulosic pulps has been well established (Berthold et al. 2004; Henniges et al. 2010). Laboratory-aged transformer board samples, manufactured of UKP and aged in the same type of oil that we used for our model experiment, became soluble by this treatment (cf. Figure S4). Complete dissolution of aged samples was not achieved without $\mathrm{NaClO}_{2}$ treatment.

Prior to fluorescence labeling of oxidized functionalities and dissolution for GPC measurement, the samples were disintegrated in $\mathrm{H}_{2} \mathrm{O}$ (step 3 in Fig. 1). In the case of FDAM-labeling $0.1 \mathrm{M}$ aqueous $\mathrm{HCl}$ solution was used instead to convert carboxylates into free carboxylic acid functionalities beforehand, a prerequisite for the subsequent labeling with the fluorescent diazomethane derivative (Bohrn et al. 2006; Potthast et al. 2006). If the samples are not fluorescence labelled prior to GPC analysis, the disintegration is directly followed by a solvent-exchange step to DMAc (overnight).

The fluorescence labelling (step 4A in Fig. 1) was done either by immersion of disintegrated samples in a CCOA/zinc acetate buffer solution $(\mathrm{pH} 4)$, or in a FDAM/DMAc solution. For complete labelling, the samples were agitated for 7 days in a water bath at $40{ }^{\circ} \mathrm{C}$ according to the standard protocol (see "Materials and methods" section), followed by solvent exchange to DMAc. Note that fluorescence labeling is of course not necessary for successful sample dissolution, it is just added when additional information about the oxidized-group profiles is required.

Each sample was initially swollen and partially dissolved for $24 \mathrm{~h}$ in a saturated solution of DMAc/ $\mathrm{LiCl}(9 \% \mathrm{LiCl}, w / \mathrm{v})$ before a small amount of ethyl isocyanate (EIC) was added to each sample,
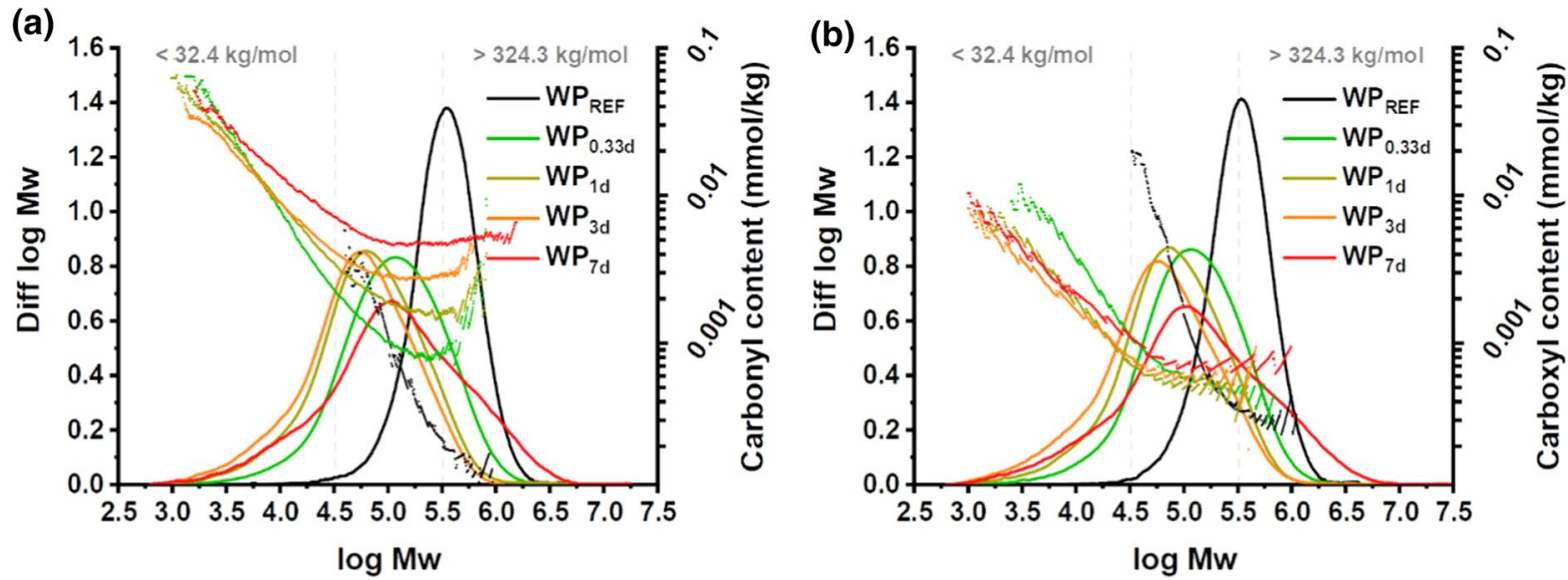

Fig. 2 MMDs (solid lines) and molar mass-dependent profiles of oxidized functionalities (scattered plots) of aged WP samples fluorescence-labelled with CCOA (a) and $\operatorname{FDAM}(\mathbf{b})$. Indices indicated the duration of the thermal aging at $170{ }^{\circ} \mathrm{C}$ 

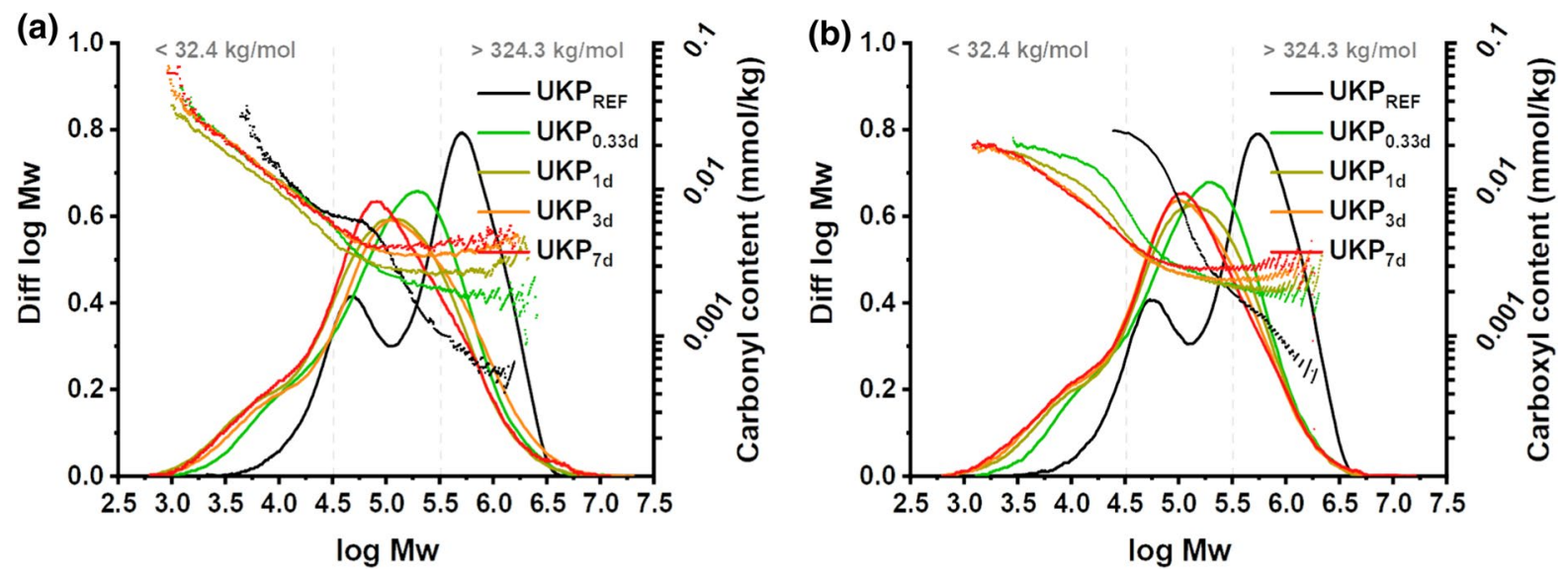

Fig. 3 MMDs (solid lines) and molar mass-dependent profiles of oxidized functionalities (scattered plots) of aged UKP samples fluorescence-labelled with CCOA (a) and FDAM (b). Indices indicated the duration of the thermal aging at $170{ }^{\circ} \mathrm{C}$

which significantly improved dissolution. Complete dissolution was reliably achieved after 7 days in total (see "Materials and methods" section, step 5 in Fig. 1) For the entire duration of sample dissolution, the vials were kept shaking. UKP samples subjected to $170{ }^{\circ} \mathrm{C}$ for 10 days and longer did not dissolve completely anymore, neither did the WP samples subjected to $170{ }^{\circ} \mathrm{C}$ for 14 days and longer (cf. Figure S5). These-heavily cross-linked- samples (see below) were excluded from the discussion since results obtained from the analysis of only partially dissolved samples can obviously not describe the sample as a whole (Sjöholm et al. 1997). Thus, the protocol in Fig. 1 is limited to oil-immersed softwood Kraft paper samples aged at $170{ }^{\circ} \mathrm{C}$ for a maximum of 7 days. This maximum ageing duration may be exceeded if the accelerated ageing is conducted at lower temperatures. After dilution and filtration, the samples were ready for GPC analysis (step 6 in Fig. 1).

Molar mass distribution \& carbohydrate composition

Figures 2 and 3 show how the MMDs (solid lines, left ordinates) of WP and UKP, respectively, are affected by thermal stress for up to 7 days. Molar massdependent profiles of oxidized functionalities are depicted as well (scattered lines, right ordinates). The WP reference featured a narrow monomodal MMD (cf. Fig. 2), whereas the UKP reference showed a typical bimodal distribution (cf. Fig. 3). It was obvious that with increasing aging times the center of the MMDs of both sample sets gradually shifted towards lower molar masses and that the MMDs became broader at the same time. This is a typical phenomenon accompanying hydrolytic degradation of cellulose (Potthast et al. 2006; Ahn et al. 2018). Interestingly, a fraction of the WP aged for 7 days $\left(\mathrm{WP}_{7 \mathrm{~d}}\right)$ significantly exceeded the maximum molecular mass found in the native reference $\left(\mathrm{WP}_{\mathrm{REF}}\right)$. This indicates that upon thermal stress the obvious process of chain cleavage (=decreased molar mass) is accompanied by a less expectable thermally induced cross-linking of cellulose, which has an opposite effect and increases molar mass. Theoretically, agglomeration in solution may contribute to this observation as well, which is discussed in more detail below.

Upon thermal aging, the characteristic bimodal MMD of softwood Kraft pulps-with the low-molar mass peak attributable to hemicelluloses and short cellulose chains (Sjöholm et al. 2000; Berthold et al. 2004) changed towards a more complex shape with a more or less pronounced shoulder on the low-molecular mass side. This transformation occurred already after $8 \mathrm{~h}\left(\mathrm{UKP}_{0.33 \mathrm{~d}}\right)$ of thermal aging. In agreement with the behavior of the WP samples, the entire MMDs shifted towards lower molar mass ranges and became broader, i.e., more dispersed. The high-molar mass fraction of the UKP sample thermally stressed for 7 days $\left(\mathrm{UKP}_{7 \mathrm{~d}}\right)$ only slightly surpassed the molecular weight of the highest molar mass fraction of the native reference $\left(\mathrm{UKP}_{\mathrm{REF}}\right)$, the thermal cross-linking 


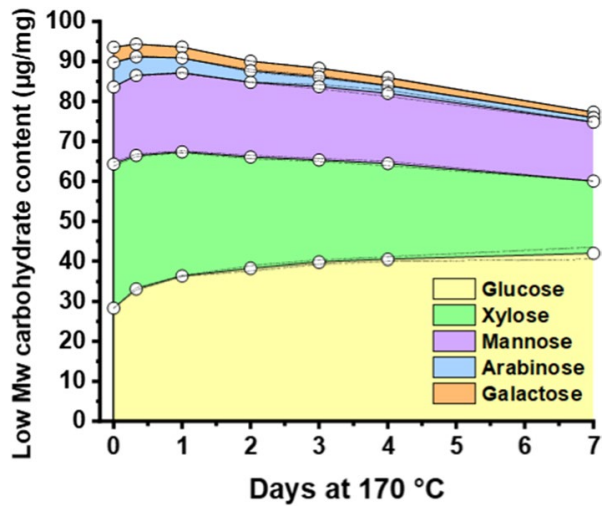

Fig. 4 Impact of accelerated ageing at $170{ }^{\circ} \mathrm{C}$ on the composition of the accessible low-molar mass carbohydrates in UKP samples, obtained by acidic methanolysis followed by gas chromatographic quantification $(n=2)$

effect thus being less pronounced than in the WP case.

The weakening of the low-molar mass peak of the UKP upon aging does not imply a complete degradation of hemicelluloses during the thermal treatment, it rather shows an increasing superposition with shorter cellulose and hemicellulose chains. Based on the quantification of the carbohydrate composition of thermally stressed samples by methanolysis, it was evident that partial decomposition of hemicelluloses took place (cf. Fig. 4). However, a significant hemicellulose amount remained even after 7 days of thermal aging. After that time, $50.2 \%$ of the backbone constituent of xylan, xylose, and $76.4 \%$ of the major backbone constituent of galactoglucomannan, mannose, remained (cf. Table S3). Note that arabinose and galactose substituents are typical for softwood hemicelluloses (Fengel and Wegener 2003) and are not to be expected in pulps from hardwood species.

Thus, a mixture of partially degraded cellulose, partially degraded hemicelluloses, and cross-linked structures co-elute over a wide range and contribute to the MMDs depicted in Fig. 3 with the levelledoff hemicellulose peak. For samples featuring such wide, polydisperse MMDs, viscosity measurements may give misleading results and great care must be taken to evaluate the data correctly (Evans and Wallis 1989). Besides this general issue, in our case the presence of hemicelluloses and of cross-linked celluloses must actually be considered for interpretation of viscosity-average $\mathrm{DP}_{\mathrm{v}}$ values of aged Kraft paper samples, which normally assumes the presence of cellulose chains only. This is another argument against the usage of viscometry data when deriving decomposition kinetics for cellulosic paper insulators. Furthermore, the carbohydrate composition of insulation papers and its changes over time must be taken into account as well for the interpretation of decomposition products accumulated in the transformer oil.

The course of molar mass parameters $\mathrm{M}_{\mathrm{n}}, \mathrm{M}_{\mathrm{w}}$, and $M_{z}$ in Fig. 5 was calculated from the samples' MMDs (see Figs. 2, 3). $M_{n}$ is the number-averaged molecular weight which emphasizes the low-molar mass material, $M_{w}$ is the weight-averaged molecular weight which reflects the high molar mass material, and $\mathrm{M}_{\mathrm{z}}$ is sensitive to the highest molar mass fraction of a sample (Potthast et al. 2015). This allowed a better monitoring of the thermal-stress effects with regard to the respective molar mass fractions.

WP samples exhibited a strong initial drop of molar mass within the first 2 days of thermal aging, across all molar mass fractions (cf. Fig. 5a and Table S4), but most pronounced for $M_{n}$. This chain
Fig. 5 Course of $M_{n}, M_{w}$, and $\mathrm{M}_{\mathrm{z}}$ during accelerated ageing at $170^{\circ} \mathrm{C}(\mathrm{n}=4), \mathbf{a}$ WP, b UKP
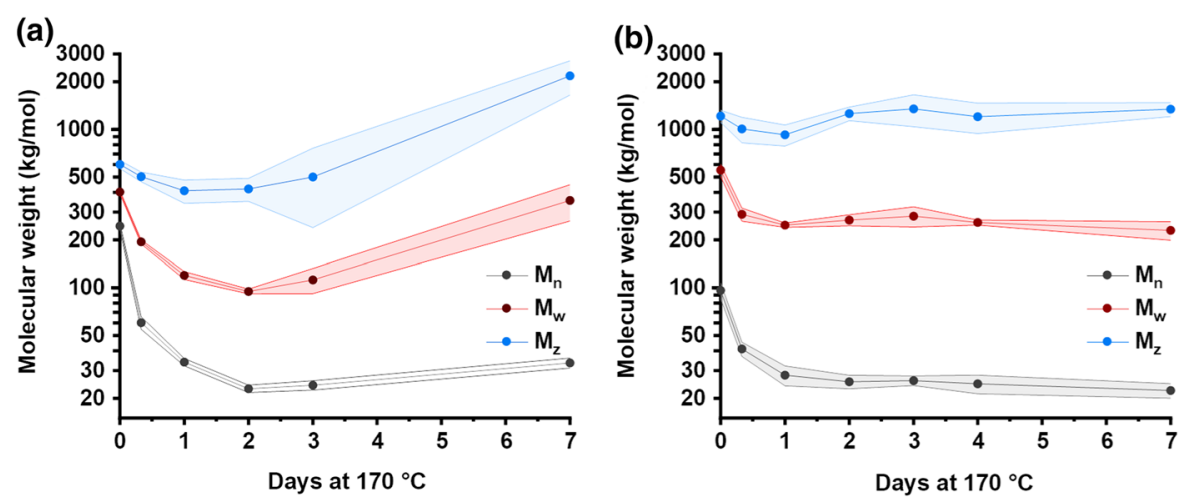
shortening is hydrolytic, catalyzed by small amounts of endogenously formed acids (from either lignocellulose or transformer oil degradation) which cannot leave the closed system of a transformer (or a reactor simulating it). The aging behavior of the "other side" of the system, the transformer oil, will be covered later in another paper. After 2 days, the parameters increased again (!), a relatively astonishing result, considering that thermal aging is normally regarded as strongly chain-degrading. The increasing molar mass was best seen by the development of $\mathrm{M}_{\mathrm{w}}$ and $\mathrm{M}_{\mathrm{z}}$ between 2 and 7 days: $M_{w-7 d}$ almost reached the initial level $\left(\mathrm{M}_{\mathrm{w}-\mathrm{REF}}\right)$ again and $\mathrm{M}_{\mathrm{z}-7 \mathrm{~d}}$ even exceeded the initial value $\mathrm{M}_{\mathrm{z}-\mathrm{REF}}$ by a factor of 3 . This corresponds to the MMD plots shown in Fig. 2 which for the aged samples showed a fraction with higher molar mass than the starting material.

Less drastic trends were observed for the UKP samples (cf. Fig. 5b and Table S5). The parameters dropped to a minimum within the first day of aging, the extent of the decrease being less pronounced than in the WP case. In contrast to WP, the $M_{n}$ and $M_{w}$ values remained rather constant upon longer aging times and only $\mathrm{M}_{\mathrm{z}}$ increased slightly after the minimum at 1 day of aging. From 2 days on, the value of $\mathrm{M}_{\mathrm{z}}$ remained rather constant, slightly above the value of the starting material, $\mathrm{M}_{\mathrm{z}-\mathrm{REF}}$. This is in correspondence with the graphic representation of the MMD in Fig. 3 (this agreement is logical as the molecular weight parameters $M_{n}, M_{w}$ and $M_{z}$ are mathematically derived from the MMD curves).

Sample conformation in solution

Apart from determining the absolute molar mass of a polymer of interest, it is possible to retrieve the polymer conformation in solution by employing a multi-angle laser light scattering (MALLS) detector. The overall scattering intensity allows calculating the molar mass of a particle and the angular dependence of the scattered laser light allows conclusions regarding the root mean square (R.M.S.) radii, or in simpler words: the "size", of the molecules in solution (Oberlerchner et al. 2015). In Fig. 6, this size measurement, as R.M.S. radius, is plotted against the molar mass of the thermally stressed paper samples. For both sample series, at a given molar mass the R.M.S. radii clearly decreased upon thermal aging or, in different words, the molar mass increased at a given radius. This means a compacting of the molecules which can be explained by the formation of intramolecular and/ or intermolecular linkages in the polymer chains, or alternatively by aggregation. Distinguishing crosslinking from aggregation is an old and well-known general problem in GPC and light scattering studies of cellulose and polysaccharides. An increased molar mass just concluded from the GPC chromatogram could, in theory, be also interpreted as aggregation of chains and as a result of a not molecularly dispersed solute. In that theoretical case, the conformation plot would not show any changes in the slopes. However, the flattening of the slopes with increasing aging time clearly supported the view that the observed molar mass gain is not the consequence of aggregation, but of true crosslinking and compacting of the molecules. Another indication in favor of crosslinking vs. aggregation is the straightness of the conformation plots. If aggregation occurs it is more pronounced for molecules with higher molecular weight than for smaller molecules. With the high-molecular weight part being more strongly affected, the conformation plots would not be straight lines, but have a "curve" or "kink". In
Fig. 6 Conformation plots (MALLS data from the GPC measurements) of aged WP (a) and UKP samples (b). The values in parentheses correspond to the slope of the linear fits. Indices indicated the duration of the thermal aging at $170{ }^{\circ} \mathrm{C}$
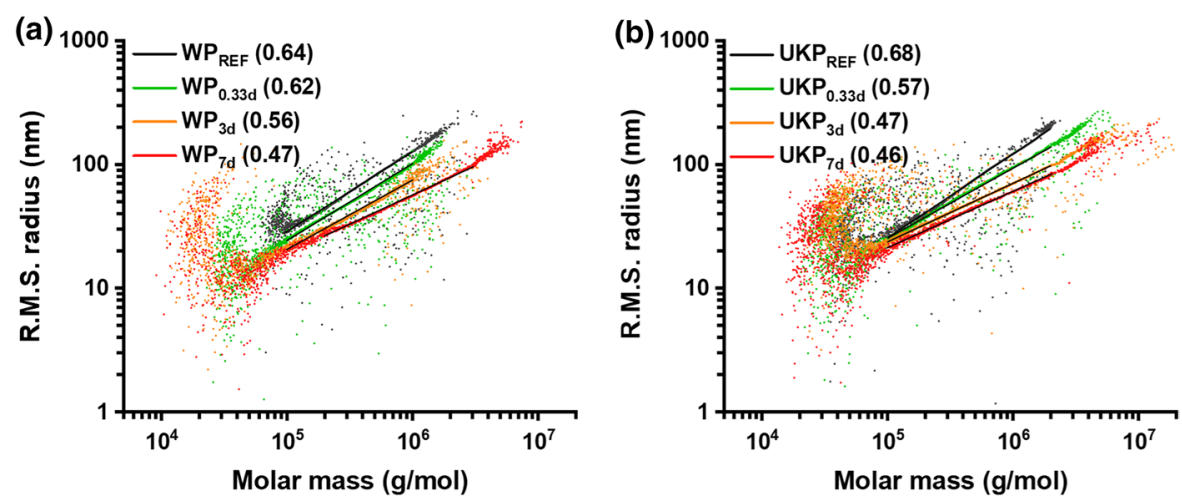
Table 1 Slopes of the linear fits of conformation plot data

\begin{tabular}{llllll}
\hline $\begin{array}{l}\text { Aging at } \\
170{ }^{\circ} \mathrm{C}(\mathrm{d})\end{array}$ & \multicolumn{2}{l}{$\mathrm{WP}(\mathrm{n}=4)$} & & \multicolumn{2}{l}{$\mathrm{UKP}(\mathrm{n}=4)$} \\
\cline { 2 - 3 } \cline { 6 - 7 } & Slope & $\mathrm{SD}$ & & Slope & SD \\
\hline 0 & 0.63 & 0.02 & & 0.68 & 0.01 \\
0.33 & 0.58 & 0.03 & & 0.56 & 0.01 \\
3 & 0.52 & 0.03 & & 0.48 & 0.00 \\
7 & 0.49 & 0.05 & & 0.48 & 0.02 \\
\hline
\end{tabular}

$1=$ stiff rod, $0.6=$ linear, random coil, 0.5 to $0.4=$ branched polymer, $0.33=$ sphere (Podzimek, 2011)

the case of crosslinking, which occurs unselectively and independently of molecular weight, i.e. between molecules of all sizes and not preferentially the highmolecular weight ones, the plots are rather straight lines, as experimentally observed.

A fit through the linear part of the double logarithmic data depiction (solid black lines in Fig. 6) can provide additional information about the molecular conformation in solution (Podzimek 2011): a slope of around 0.6 is typical for a linear, randomly coiled polymer in solution, whereas a slope of 0.5 to 0.4 indicates branching. Based on the obtained values, it was obvious that with increasing aging times the carbohydrate polymers (cellulose and hemicelluloses) in solution exhibited an increasingly branched, i.e., crosslinked, structure (cf. Fig. 6 and Table 1). These results are consistent with analytical data from burned paper samples (Ahn et al. 2018), which showed the same crosslinking/compacting effect.

The results shown in Figs. 2, 3, 5, and 6 clearly demonstrated that under the given conditions of thermal aging, chain scission and covalent crosslinking occurred simultaneously. If the samples were subjected to $170{ }^{\circ} \mathrm{C}$ for several days, an increasing number of crosslinks or side chains (branches) was introduced into the polymer structure. Both phenomena occurred independently of the paper type and independent on molar mass ranges, i.e., through the entire molar mass range. Only in the plots of molar mass versus retention volume of the samples $\mathrm{WP}_{7 \mathrm{~d}}$ and $\mathrm{UKP}_{7 \mathrm{~d}}$, a slight deviation from the linear relation was visible in the high molar mass range in some cases (cf. Figure S2). The other samples did not exhibit this behavior. Thus, in case of $\mathrm{WP}_{7 \mathrm{~d}}$ and $\mathrm{UKP}_{7 \mathrm{~d}}$, also aggregation of polymers in solution may have occurred. As mentioned above, this phenomenon would not change the slope over the entire molar mass range.

Carbonyl and carboxyl functionalities

The fluorescence signal intensity of labeled samples provides the absolute number of oxidized groupscarbonyl groups in the case of CCOA labeling and carboxyl groups with FDAM labeling and due to the combination with a GPC/MALLS system, also the molar mass-dependent profiles of oxidized functionalities (cf. Figs. 2, 3). The absolute contents of $\mathrm{CO}$ and $\mathrm{COOH}$ and their time courses are shown in Fig. 7.

CCOA is a selective fluorescence label for aldehyde and keto functionalities (Röhrling et al. 2002a, b; Potthast et al. 2005, 2006), which also covers the reducing end groups (REG) of carbohydrates. The carbonyl group content of UKP before ageing was $19.5 \mathrm{mmol} / \mathrm{kg}$ and increased up to $46.9 \mathrm{mmol} / \mathrm{kg}$ after 7 days of aging. The initial carbonyl group content of
Fig. 7 Courses of the carbonyl group content (a) and carboxyl group content (b) in the samples upon accelerated ageing at $170{ }^{\circ} \mathrm{C}$
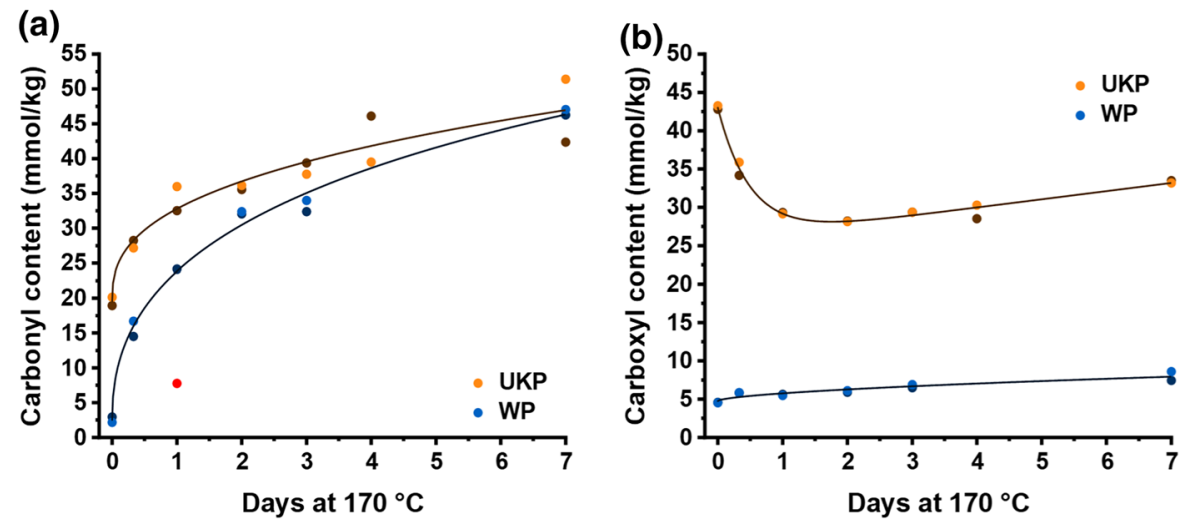
WP samples was $2.6 \mathrm{mmol} / \mathrm{kg}$ before and $46.7 \mathrm{mmol} /$ $\mathrm{kg}$ after heat exposure, the two celluloses thus exhibiting almost the same final carbonyl values. This increase of carbonyl functionalities can be explained by the thermal elimination of water molecules from the carbohydrate backbone resulting in an unsaturated pyranose ring and, by immediate keto-enol tautomerism, in an anhydro-ketosugar (Scheirs et al. 2001; Hosoya et al. 2018). This thermally induced elimination mechanism starts at around $150^{\circ} \mathrm{C}$ (Klemm et al. 1998).

Figure $7 \mathrm{~b}$ shows the course of the overall content of carboxyl groups in the two studied paper types upon thermal aging. The FDAM label selectively marks carboxyl groups of uronic acid moieties (Bohrn et al. 2006; Potthast et al. 2006), while carboxylates (salt forms), lactones (oxidized REGs) and esters are not labeled. Obviously, either decarboxylation processes or esterifications took place in UKP within the first 2 days of thermal stress: the initial carboxyl content of $43.0 \mathrm{mmol} / \mathrm{kg}$ decreased to $28.2 \mathrm{mmol} / \mathrm{kg}$. The conversion of carboxyl-bearing side chains (4-O-methyl-glucuronic acid moieties) in xylan to unstable hexeneuronic acid moieties and then further to low-molecular weight degradation products (Rosenau et al. 2017b) might contribute to this $\mathrm{COOH}$-decrease. Formation of lactones of carboxylic acid groups and neighboring hydroxyl groups could add to this effect as well, since lactone formation would be favored by acidic environments and elevated temperatures (Potthast et al. 2006). Prolonged thermal stress slightly increased the carboxyl content, which reached $33.3 \mathrm{mmol} / \mathrm{kg}$ after 7 days. A comparable absolute increase was also seen for the WP sample series $\left(\mathrm{WP}_{\mathrm{REF}}\right.$ : $4.6 \mathrm{mmol} / \mathrm{kg}, \mathrm{WP}_{7 \mathrm{~d}}$ : $8.0 \mathrm{mmol} / \mathrm{kg}$ ), just starting from a rather low initial level. The rather small $\mathrm{COOH}$ increase will be due to autoxidation processes arising from oxygen traces (Kolar 1997) or rearrangement of diketo structures, for instance. Both would be direct consequence of the thermal stress.
Fig. 8 Development of the carbonyl group content (a) and carboxyl group ated thermal aging of WP samples within three molarmass ranges, $<32.4 \mathrm{~kg} /$ $\mathrm{mol}, 32.4$ to $324.3 \mathrm{~kg} / \mathrm{mol}$ and $>324.3 \mathrm{~kg} / \mathrm{mol}$ content (b) upon acceler-
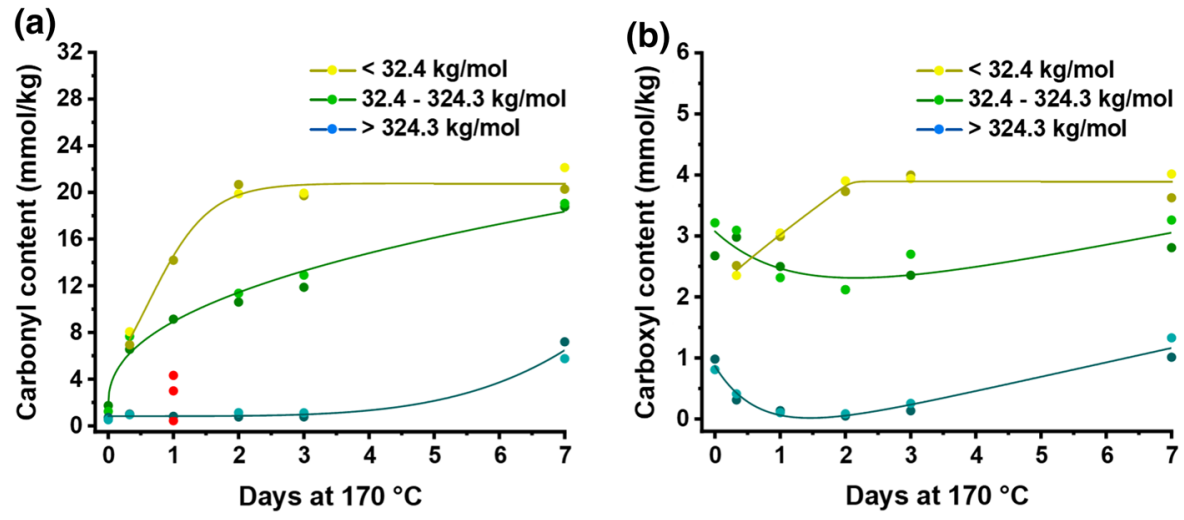

Fig. 9 Development of the carbonyl group content (a) and carboxyl group content (b) upon accelerated thermal aging of UKP samples within three molar mass ranges, $<32.4 \mathrm{~kg} /$ mol, 32.4 to $324.3 \mathrm{~kg} / \mathrm{mol}$ and $>324.3 \mathrm{~kg} / \mathrm{mol}$
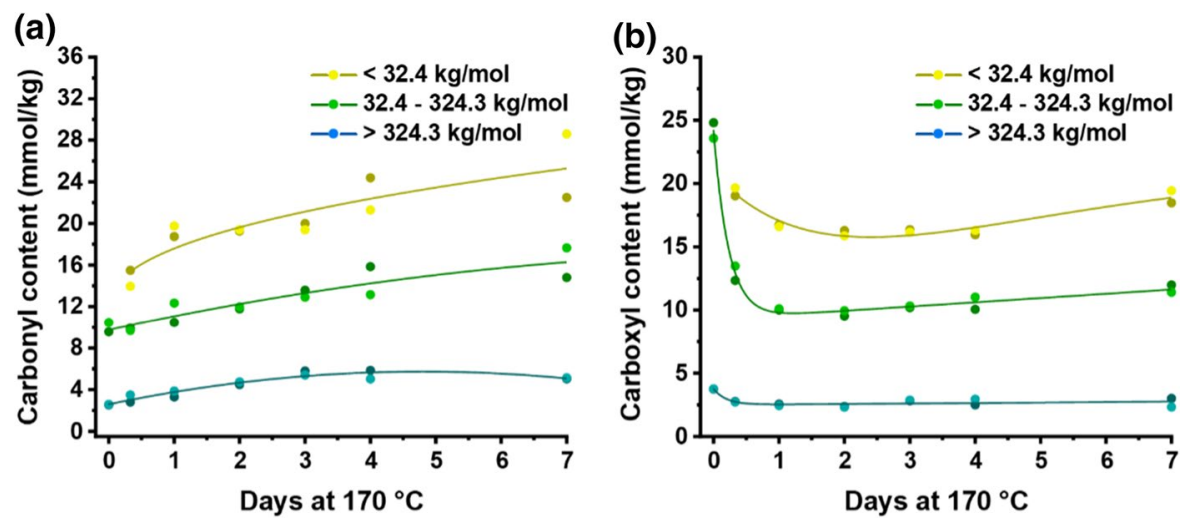
One of the advantages of combining fluorescence labelling of oxidized functionalities with a GPC/ MALLS system is the possibility of analyzing the molar mass dependency of carbonyl and carboxyl changes in more detail (for examples see: Henniges et al. 2013, Ahn et al. 2019b). Figures 8 and 9 show the development of the carbonyl and the carboxyl group content (Ahn et al. 2019a) in WP and UKP samples, respectively, for the low-molar mass fraction $<32.4 \mathrm{~kg} / \mathrm{mol}$, the medium-molar mass range $32.4-324.3 \mathrm{~kg} / \mathrm{mol}$ and the high-molar mass region $>324.3 \mathrm{~kg} / \mathrm{mol}$.

For WP, a nearly linear increase of carbonyl groups was observed from $8 \mathrm{~h}$ to 7 days in the main molar mass fraction from 32.4 to $324.3 \mathrm{~kg} / \mathrm{mol}$ (Fig. 8a). The carbonyls in the low-molar mass region increased more strongly up to two days and remained constant afterwards, while high-molar mass region was largely inert and showed only a slight carbonyl increase at extended aging times (7 days). This behavior reflects the higher mobility and thus reactivity of the shorter cellulose chains. In principle the same courses were seen for the carboxyl groups (Fig. 8b); an initial $\mathrm{COOH}$ loss $(<1 \mathrm{~d})$ was compensated by a constant slight increase in the medium and high molar mass ranges from day 2 on. While the initial, faster $\mathrm{COOH}-$ consuming processes are likely to be decarboxylations and esterification/lactone formations, the later slow $\mathrm{COOH}$ increase is supposed to be caused by autoxidation and thermal rearrangements (see above). The initial, faster increase in the carboxyl content in the low-molar mass fraction $(<32.4 \mathrm{~kg} / \mathrm{mol})$ counteracted the decrease in the medium- and high-molar mass ranges and coincided with the phase of decreasing average molecular weight $\left(\mathrm{M}_{\mathrm{n}}, \mathrm{M}_{\mathrm{w}}\right.$, and $\left.\mathrm{M}_{\mathrm{z}}\right)$ of the WP samples, which thus might simply be a consequence of hydrolytic, acid-catalyzed chain cleavage of the cellulose polymers. With thermally induced cross-linking becoming more and more dominant, the hydrolytic cleavage is increasingly compensated and even overcompensated.

Since UKP samples were treated with $\mathrm{NaClO}_{2}$ prior to dissolution, they do not contain reducing end groups (aldehydes masked as hemiacetal) and alongchain aldehyde groups (C-6), but merely along-chain keto functionalities (C-2, C-3). Free and masked aldehydes are oxidized to the $\mathrm{COOH}$ stage by the reagent. A uniform, slow, almost linear increase of carbonyl groups was detected across all molar mass fractions for the whole aging time (Fig. 9a), which corresponds to the generation of new reducing ends by chain cleavage. The strong decrease of the overall carboxyl group content upon aging (Fig. 7b) could be traced back to the medium-molar mass fraction (Fig. 9b). This molar mass fraction also featured the hemicellulose peak of the initial bimodal MMD of the UKP reference (cf. Fig. 3). Considering this and the fact that the thermal degradation of oil immersed paper proceeds through processes acidifying the system under accumulation of acidic byproducts (Jusner et al. 2021b), it seemed plausible that under such conditions the initial drop of the carboxyl group content of UKP samples would mostly reflect the decomposition of hexeneuronic moieties from xylan which are known to be unstable already under mildly acidic conditions (Rosenau et al. 2017b). Note that the concentration of $\mathrm{COOH}$ in cellulose might well decrease, while the acidity in the reaction system as a whole can strongly increase through low-molecular weight acids which cannot leave the sealed ampoule-as they cannot leave the power transformer in reality.

In the literature, the phenomenon of thermal crosslinking of cellulose and paper has been discussed and mechanisms have been suggested (Klemm et al. 1998; Kato and Cameron 1999; Fernandes Diniz et al. 2004; Pönni et al. 2012). These include intermolecular hemiacetal or hemiketal bridges, similar to the chemistry of "dialdehyde cellulose" (DAC) (Amer et al. 2016) obtained by periodate oxidation of cellulose, where this extensive crosslinking is largely responsible for the observed material properties (Plappert et al. 2018). Also, intermolecular esterification and ether formation contribute to crosslinking, the latter reaction type becoming increasingly favored at temperatures above $150{ }^{\circ} \mathrm{C}$.

Recently, another potential mechanism for thermally induced simultaneous cross-linking and scission of cellulose chains has been discussed. It was demonstrated that two adjacent, oxidized glucopyranose units of cellulose, each having a 3-keto moiety, form a 2,4':2',4- dianhydride, a "diketo dimer", which results in the cleavage of two $\beta$-1,4-gycosidic bonds (intramolecular bonds) and simultaneous formation of two new intermolecular linkages between $\mathrm{C} 2$ and C4 of the respective monomers (Yoneda et al. 2008; Rosenau et al. 2017a). This structure has been isolated from artificially aged, oxidized beech sulfite pulp and the formation is favored by acid environments as 
well as by heat. This mechanism would not cause a net consumption of carbonyl groups since the resulting diketo dimer features 2 keto groups as do the two individual oxidized starting units.

While our results clearly demonstrate that thermal aging under conditions simulating long-term service in power transformers causes crosslinking, we are at present not able to confirm the presence of any particular crosslinking mechanism or rule out another based on the available data. There are several possible mechanisms that could be responsible. A proof of the chemical nature of the interchain links would require isotopically $\left({ }^{13} \mathrm{C}\right)$ labelled cellulose in combination with special NMR techniques.

\section{Conclusions}

Papers made of Kraft pulp, which are used as insulation material in transformers, could not be investigated by GPC/MALLS so far because they were insoluble in the standard eluent (DMAc/LiCl). A combination of three special pretreatments, extraction of the transformer oils, chlorite oxidation for lignin removal, and addition of catalytic amounts of EIC during the dissolution process, solved this problem. Thus, for the first time, the aging processes in such cellulosic insulation materials can be studied not only indirectly by observing the degradation products in the oil or by means of a molar mass sum parameter from viscosity measurements, but directly by means of the molar mass distribution and the profiles of oxidized groups. It is known from the literature that all three pretreatment methods do not change the molecular weight distribution of the pulps, therefore it can be assumed that the obtained distributions are largely free of artifacts and reflect the "true" state of the pulps sufficiently well.

As previously assumed, thermal stress leads to an increasing reduction in molecular weight. What is new, however, is that crosslinking reactions were observed to occur concurrently with degradation. The evaluation of the GPC data of the pulps thermally aged over a longer period of time shows a fraction with significantly increased molecular weight and more compact-because crosslinked-molecules with lower R.M.S. radii than the starting pulps. This thermal crosslinking appears to be a general effect of thermal stressing of pulps. Also in this study, the effects were observed for both sample types, WP and UKP.

The analysis of the carbohydrate composition revealed that a significant amount of hemicelluloses withstood the relatively drastic ageing conditions and remained within the insulator paper. Previous theories rather proposed a far-reaching hemicellulose degradation with rather little cellulose degradation. The current results, by contrast, show that both hemicelluloses and cellulose are degraded, seen from a diminished hemicellulose peak and an overall shift of the molar mass distribution towards smaller values. Thus, the paper contains a mixture of partially degraded cellulose, partially degraded hemicelluloses, and crosslinked structures that all contribute to the observed molar mass distributions.

The determination of the $\mathrm{DP}_{\mathrm{V}}$ sum parameter from viscosity measurements is not recommended for the case of aged transformer papers for two reasons. First, especially at high dispersity of the MMDs, an averaging $\mathrm{DP}_{\mathrm{V}}$ value obtained from viscosity measurements cannot reflect the dynamic changes during thermal aging (degradation and crosslinking). Second, the alkalinity of the organometallic solvents causes degradation of oxidized pulps by beta-elimination: the more carbonyl groups contained along the chain, the greater the degradation and the error introduced. However, an argument in favor of viscosity measurements are the lower costs and the faster and easier sample preparation. A GPC/MALLS system is quite expensive and the approach more complex. It is not a means of quick screening or quality control, but can provide an abundance of additional information which is not accessible by viscosity measurements.

The introduced protocol proved its suitability for the GPC/MALLS characterization of thermally stressed, oil-immersed paper samples and was able to provide insights into the thermal decomposition of insulator paper in unprecedented detail. The method seems to be a good basis for studying thermally loaded papers in general, both in terms of their final state and in terms of kinetics of accelerated aging. Thus, we hope that the present work can contribute to a better overall understanding of thermal aging processes of celluloses and papers.

Authors' contributions PJ, AP and TR contributed to the study conception and design. The conditions for the mild $\mathrm{NaClO}_{2}$ delignification preserving the samples' original molar 
mass distributions were elaborated by FB. Material preparation, data collection and analysis were performed by all authors. The first draft of the manuscript was written by PJ and TR and all authors commented on previous versions of the manuscript. All authors read and approved the final manuscript.

Funding Open access funding provided by University of Natural Resources and Life Sciences Vienna (BOKU). The financial support by the Austrian Biorefinery Center Tulln $(\mathrm{ABCT})$ is gratefully acknowledged.

Availability of data and material Data available from the authors upon request.

Code availability Not applicable.

\section{Declarations}

Conflict of interest The authors declare that thet have no competing interest.

Consent for publication All authors agreed to the publication in the submitted form.

Open Access This article is licensed under a Creative Commons Attribution 4.0 International License, which permits use, sharing, adaptation, distribution and reproduction in any medium or format, as long as you give appropriate credit to the original author(s) and the source, provide a link to the Creative Commons licence, and indicate if changes were made. The images or other third party material in this article are included in the article's Creative Commons licence, unless indicated otherwise in a credit line to the material. If material is not included in the article's Creative Commons licence and your intended use is not permitted by statutory regulation or exceeds the permitted use, you will need to obtain permission directly from the copyright holder. To view a copy of this licence, visit http://creativecommons.org/licenses/by/4.0/.

\section{References}

Ahn K, Schedl A, Zweckmair T, Rosenau T, Potthast A (2018) Fire-induced structural changes and long-term stability of burned historical rag papers. Sci Rep 8:12036

Ahn K, Zaccaron S, Rosenau T, Potthast A (2019a) How alkaline solvents in viscosity measurements affect data for oxidatively damaged celluloses: cupri-ethylenediamine. Biomacromol 20:4117-4125

Ahn K, Zaccaron S, Zwirchmayr NS, Hettegger H, Hofinger A, Bacher M, Henniges U, Hosoya T, Potthast A, Rosenau T (2019b) Yellowing and brightness reversion of celluloses: $\mathrm{CO}$ or $\mathrm{COOH}$, who is the culprit? Cellulose 26(1):429-444

Amer H, Nypelö T, Sulaeva I, Bacher M, Henniges U, Potthast A, Rosenau T (2016) Structural elucidation of periodate oxidized polysaccharides: spectroscopic investigation and thermal property of xylan dialdehyde. Biomacromolecules 17(9):2972-2980

Arroyo-Fernandez OH, Fofana I, Jalbert J, Rodriguez E, Rodriguez LB, Ryadi M (2017) Assessing changes in thermally upgraded papers with different nitrogen contents under accelerated aging. IEEE Trans Dielect Elect in 24:1829-1839

Becker M, Ahn K, Bacher M, Xu C, Sundberg A, Willför S, Rosenau T, Potthast A (2021) Comparative hydrolysis analysis of cellulose samples and aspects of its application in conservation science. Cellulose 28:8719-8734

Berthold F, Gustafsson K, Berggren R, Sjöholm E, Lindström M (2004) Dissolution of softwood kraft pulps by direct derivatization in lithium chloride/, , N-dimethylacetamide. J Appl Polym Sci 94:424-431

Bohrn R, Potthast A, Schiehser S, Rosenau T, Sixta H, Kosma P (2006) The FDAM method: Determination of carboxyl profiles in cellulosic materials by combining group-selective fluorescence labeling with GPC. Biomacromol 7:1743-1750

Chrapava S, Touraud D, Rosenau T, Potthast A, Kunz W (2003) The investigation of the influence of water and temperature on the $\mathrm{LiCl} / \mathrm{DMAc} /$ cellulose system. Phys Chem Chem Phys 5:1842-1847

Dence CW (1992) The Determination of Lignin. In: Lin SY, Dence CW (eds) Methods in Lignin chemistry. Springer Berlin Heidelberg

Emsley AM, Stevens GC (1994a) Kinetics and mechanisms of the low-temperature degradation of cellulose. Cellulose 1:26-56

Emsley AM, Stevens GC (1994b) Review of chemical indicators of degradation of cellulosic electrical paper insulation in oil-filled transformers. IEE P-Sci Meas Tech 141:324-334

Emsley AM, Ali M, Heywood RJ (2000) A size exclusion chromatography study of cellulose degradation. Polymer 41:8513-8521

Evans R, Wallis AFA (1989) Cellulose molecular weights determined by viscometry. J Appl Polym Sci 37:2331-2340

Fengel D, Wegener G (2003) 5. Polyoses (Hemicelluloses). In: Fengel D, Wegener G (eds) Wood: chemistry, ultrastructure, reactions. Verlag Kessel, Remagen

Fernandes Diniz JMB, Gil MH, Castro JAAM (2004) Hornification - its origin and interpretation in wood pulps. Wood Sci Technol 37:489-494

Henniges U, Schiehser S, Rosenau T, Potthast A (2010) Cellulose solubility: dissolution and analysis of "problematic" cellulose pulps in the solvent system DMAc/LiCl. ACS Symp Ser 1033:165-177

Henniges U, Kostic M, Borgards A, Rosenau T, Potthast A (2011) Dissolution behaviour of different celluloses. Biomacromol 12(4):871-879

Henniges U, Hasani M, Potthast A, Westman G, Rosenau T (2013) Electron beam irradiation of cellulosic materialsopportunities and limitations. Materials 6(5):1584-1598

Henniges U, Vejdovszky P, Siller M, Jeong MJ, Rosenau T, Potthast A (2014) Finally dissolved! activation procedures to dissolve cellulose in $\mathrm{DMAc} / \mathrm{LiCl}$ prior to size exclusion chromatography analysis-a review. Curr Chromatogr 1(1):52-68 
Hill DJT, Le TT, Darveniza M, Saha T (1995) A study of degradation of cellulosic insulation materials in a power transformer, part 1. Molecular weight study of cellulose insulation paper. Polym Degrad Stab 48:79-87

Hosoya T, Takano T, Kosma P, Rosenau T (2014) Theoretical evidence for the presence of oxacarbenium ions in chemical glycoside synthesis. J Org Chem 79(17):7889-7894

Hosoya T, Bacher M, Potthast A, Elder T, Rosenau T (2018) Insights into degradation pathways of oxidized anhydroglucose units in cellulose by beta-alkoxy-elimination - a combined theoretical and experimental approach. Cellulose 25(7):3797-3814

Jalbert J, Rodriguez-Celis E, Duchesne S, Morin B, Ryadi M, Gilbert R (2014) Kinetics of the production of chain-end groups and methanol from the depolymerization of cellulose during the ageing of paper/oil systems. Part 3: extension of the study under temperature conditions over 120 ${ }^{\circ} \mathrm{C}$. Cellulose 22:829-848

Jusner P, Bacher M, Simon J, Bausch F, Khaliliyan H, Schiehser S, Sumerskii I, Schwaiger E, Potthast A, Rosenau $T$ (2021a) Analyzing the effects of thermal stress on insulator papers by solid-state 13C NMR spectroscopy. Cellulose

Jusner P, Schwaiger E, Potthast A, Rosenau T (2021b) Thermal stability of cellulose insulation in electrical power transformers-a review. Carbohydr Polym 252:

Kato KL, Cameron RE (1999) A review of the relationship between thermally-accelerated ageing of paper and hornification. Cellulose 6:23-40

Kes M, Christensen BE (2013) Degradation of cellulosic insulation in power transformers: a SEC-MALLS study of artificially aged transformer papers. Cellulose 20:2003-2011

Klemm D, Philipp B, Heinze T, Heinze U, Wagenknecht W (1998) General Considerations on Structure and Reactivity of Cellulose: Section 2.3-2.3.7. In: Klemm D, Philipp B, Heinze T, Heinze U, Wagenknecht W (eds) Comprehensive cellulose chemistry: fundamentals and analytical methods, vol 1

Kolar J (1997) Mechanism of autoxidative degradation of cellulose. Restaurator 18:163

Krause C (2012) Power transformer insulation - history, technology and design. IEEE Trans Dielect Elect In 19:1941-1947

Krause C, Dreier L, Fehlmann A, Cross J (2014) The degree of polymerization of cellulosic insulation: review of measuring technologies and its significance on equipment. 2014 IEEE electrical insulation conference (EIC), pp 267-271

Li Y, Zhou K, Li ZR, Zhang QG (2020) Research on the electrical aging characteristics of oil-impregnated pressboard under partial discharges. IEEE Trans Dielect Elect in 27:42-48

Lundgaard LE, Hansen W, Linhjell D, Painter TJ (2004) Aging of oil-impregnated paper in power transformers. IEEE Trans Power Deliver 19:230-239

Oberlerchner JT, Rosenau T, Potthast A (2015) Overview of methods for the direct molar mass determination of cellulose. Molecules 20:10313-10341

Plappert S, Quraishi S, Pircher N, Mikkonen K, Veigel S, Klinger KM, Potthast A, Rosenau T, Liebner F (2018) Transparent, flexible and strong 2,3-dialdehyde cellulose films with high oxygen barrier properties. Biomacromol 19(7):2969-2978

Podzimek S (2011) Combination of SEC and Light Scattering. In: Podzimek S (ed) Light scattering, size exclusion chromatography and asymmetric flow field flow fractionation. John Wiley \& Sons, Inc., Hoboken, New Jersey, USA

Pönni R, Vuorinen T, Kontturi E (2012) Proposed nano-scale coalescence of cellulose in chemical pulp fibers during technical treatments. BioResources 7:6077-6108

Potthast A, Rohrling A, Rosenau T, Borgards A, Sixta H, Kosma P (2003) A novel method for the determination of carbonyl groups in cellulosics by fluorescence labeling. 3. Monitoring Oxidative Processes Biomacromolecules 4:743-749

Potthast A, Radosta S, Saake B, Lebioda S, Heinze T, Henniges U, Isogai A, Koschella A, Kosma P, Rosenau T, Schiehser S, Sixta H, Strlič M, Strobin G, Vorwerg W, Wetzel H (2015) Comparison testing of methods for gel permeation chromatography of cellulose: coming closer to a standard protocol. Cellulose 22:1591-1613

Potthast A, Rosenau T, Sixta H, Kosma P (2002a) Degradation of cellulosic materials by heating in $\mathrm{DMAc} / \mathrm{LiCl}$. Tetrahedron Lett 43:7757-7759

Potthast A, Rosenau T, Sartori J, Sixta H, Kosma P (2002b) Hydrolytic processes and condensation reactions in the cellulose solvent system $\mathrm{N}$, N-dimethylacetamide/lithium chloride. Part 2: Degradation of cellulose. Polymer 44(1):7-17

Potthast A, Rosenau T, Kosma P (2006) Analysis of oxidized functionalities in cellulose. In: Klemm D (ed) Polysaccharides II. Springer-Verlag, Berlin

Potthast A, Rosenau T, Kosma P, Saariaho AM, Vuorinen $\mathrm{T}$ (2005) On the nature of carbonyl groups in cellulosic pulps. Cellulose 12(1):43-50

Prevost TA, Oommen TV (2006) Cellulose insulation in oilfilled power transformers: Part I-history and development. IEEE Electr Insul M 22:28-35

Röhrling J, Potthast A, Rosenau T, Lange T, Borgards A, Sixta H, Kosma P (2002a) A novel method for the determination of carbonyl groups in cellulosics by fluorescence labeling. 2. Validation and Applications Biomacromolecules 3:969-975

Röhrling J, Potthast A, Rosenau T, Lange T, Ebner G, Sixta H, Kosma P (2002b) A novel method for the determination of carbonyl groups in cellulosics by fluorescence labeling. 1 . Method Dev Biomacromol 3:959-968

Rosenau T, Potthast A, Kosma P, Hosoya T, Henniges U, Mereiter K, French AD (2017a) 2,4':2',4 Dianhydride of 3-keto-glucoside, a precursor to chromophores of aged, yellow cellulose, and its weak interactions. Cellulose 24:1227-1234

Rosenau T, Potthast A, Zwirchmayr NS, Hettegger H, Plasser F, Hosoya T, Bacher M, Krainz K, Dietz T (2017b) Chromophores from hexeneuronic acids: identification of HexA-derived chromophores. Cellulose 24:3671-3687

Scheirs J, Camino G, Tumiatti W (2001) Overview of water evolution during the thermal degradation of cellulose. Eur Polym J 37:933-942

Sjöholm E, Gustafsson K, Pettersson B, Colmsjö A (1997) Characterization of the cellulosic residues from lithium 
chloride/N, N-dimethylacetamide dissolution of softwood kraft pulp. Carbohydr Polym 32:57-63

Sjöholm E, Gustafsson K, Berthold F, Colmsjö A (2000) Influence of the carbohydrate composition on the molecular weight distribution of kraft pulps. Carbohydr Polym 41:1-7

Soares S, Ricardo NMPS, Heatley F, Rodrigues E (2001) Low temperature thermal degradation of cellulosic insulating paper in air and transformer oil. Polym Int 50:303-308

Sundberg A, Sundberg K, Lillandt C, Holmhom B (1996) Determination of hemicelluloses and pectins in wood and pulp fibres by acid methanolysis and gas chromatography. Nord Pulp Pap Res J 11:216-219

Yoneda Y, Mereiter K, Jäger C, Brecker L, Kosma P, Rosenau T, French A (2008) van der Waals versus hydrogen-bonding forces in a crystalline analog of cellotetraose: cyclohexyl 4'-O-cyclohexyl $\beta$-d-cellobioside cyclohexane solvate. J Am Chem Soc 130(49):16678-16690

Zaccaron S, Henniges U, Potthast A, Rosenau T (2020) How alkaline solvents in viscosity measurements affect data for oxidatively damaged celluloses. Cuoxam and Cadoxen. Carbohydr Polym 240:

Publisher's Note Springer Nature remains neutral with regard to jurisdictional claims in published maps and institutional affiliations. 